\title{
Exploring the Online Learning Self-efficacy of Teacher Education Students at the Laguna State Polytechnic University: Basis for Transition to Flexible Learning System
}

\author{
Edilberto Z. Andal EdD ${ }^{1, *}$, Albert Andry E. Panergayo², Maria Remedios G. Almanza² \\ ${ }^{1}$ College of Teacher Education \& Graduate Studies and Applied Research, Laguna State Polytechnic University, San Pablo City, \\ Laguna 4000, Philippines \\ ${ }^{2}$ College of Teacher Education, Laguna State Polytechnic University, San Pablo City, Laguna 4000, Philippines
}

Received August 18, 2020; Revised October 18, 2020; Accepted October 24, 2020

\begin{abstract}
Cite This Paper in the following Citation Styles
(a): [1] Edilberto Z. Andal EdD, Albert Andry E. Panergayo, Maria Remedios G. Almanza, "Exploring the Online Learning Self-efficacy of Teacher Education Students at the Laguna State Polytechnic University: Basis for Transition to Flexible Learning System," Universal Journal of Educational Research, Vol. 8, No. 12, pp. 6598-6608, 2020. DOI: 10.13189/ujer.2020.081224.
\end{abstract}

(b): Edilberto Z. Andal EdD, Albert Andry E. Panergayo, Maria Remedios G. Almanza (2020). Exploring the Online Learning Self-efficacy of Teacher Education Students at the Laguna State Polytechnic University: Basis for Transition to Flexible Learning System. Universal Journal of Educational Research, 8(12), 6598-6608. DOI: 10.13189/ujer.2020.081224.

Copyright $\bigcirc 2020$ by authors, all rights reserved. Authors agree that this article remains permanently open access under the terms of the Creative Commons Attribution License 4.0 International License

\begin{abstract}
The global pandemic due to the emergence of COVID-19 impacted the education sector causing the dramatic shift from conventional to flexible learning. To sustain learning continuity, online learning modality rises as a promising instructional response to the pandemic. This study utilized correlational research to explore the factors influencing the online learning self-efficacy of the 387 (57\%) teacher education students. It also described the online learning self-efficacy, online readiness, coping strategies, and familiarity and capability of students to educational technology tools. The content-validated and researcher-made instrument which established an excellent reliability index (0.96), was administered via Google forms. Multiple regression analysis was employed to determine the significant predictors of the students' online learning self-efficacy. The results revealed that online readiness, coping strategies, and familiarity and capability significantly explain the variation in the student's self-efficacy to learn online. The administration and the teachers may consider the students' computer skills, reflect on their readiness for online learning, and understand their coping mechanisms in the digital classroom. These factors
\end{abstract}

could be sourced out in developing instructional materials to meet the diverse needs of the students.

Keywords Online Learning Self-efficacy, Online Learning Readiness, Coping Strategy, Familiarity and Capability

\section{Introduction}

The emergence of the Corona Virus Disease-2019 (COVID-19) pandemic prompted educational institutions to shift from the classroom setting to a flexible learning system. This system is designed to provide learning options that meet the demands of students in various aspects such as accessibility and customizability. Further, technology integration to education is not new, however, the pandemic has certainly shifted the view on educational technology from want to necessity. Online learning has already become the norm for higher education institutions (HEIs) [1]. Since 1990, HEIs have largely invested in digital 
learning resources to thrive in the online learning environment [2]. Online education is a type of distance learning that implements instruction in a virtual classroom, where the teacher and the learners can interact over the internet. It is claimed that any learning arrangement with considerable elements of online learning is considered as online learning, whether it is blended/hybrid or purely online [3]. The flexibility of time and place for learning is the most important feature of online education $[4,5]$. This makes it an appropriate instructional response to the COVID-19 pandemic, as face-to-face classes are not feasible.

In the Philippines, the Commission on Higher Education (CHED) encouraged State Universities and Colleges (SUCs) to conduct studies about the adoption of comprehensive flexible learning modalities in place of face-to-face classes to continue the delivery of higher education in the country. CHED directed SUCs and other HEIs to craft their respective learning management systems in preparation for incoming school calendar year adopting a flexible learning system. Flexible learning options include online learning along with modular learning, blended learning, and distance learning. Online learning is not a novel concept for Philippine SUCs and HEIs. It has been present for decades in the higher educational system, from being a supplement to face-to-face classes to extensive use of the learning management system as an academic venue for lesson content sharing and learning assessment. Under the whole-of-government approach to combat the COVID-19, the CHED is working with other state agencies to capacitate the faculty of HEIs in preparation for the new normal in education. Moreover, students must also be prepared in shifting from the traditional classroom to an online learning environment. Students' readiness, ICT capability, and perspective towards online learning play a vital role in the successful implementation of the program. These must be considered to keep the students adept despite the educational transition.

Understanding the role of the students is crucial to the successful implementation of online learning. This informs the stakeholders and policymakers about the type of support to be given to the learners [6]. The characteristics of the learners must be recognized to provide a basis for the development of an effective instructional intervention. In the study conducted by Islam, Rahim, Liang, and Momtaz (2011), age, the program of study, and level of education were revealed to have a significant effect on the effectiveness of E-learning. Shen, Cho, Tsai, and Marra (2013) further revealed that the number of online courses taken, gender, and academic status predicts online learning self-efficacy. A similar study conducted by Naresh, Reddy, and Pricilda (2016) revealed that gender, educational background, and internet usages do have a high influence on e-learning readiness. Further, Owate, Afolabi, and Akanwa (2017) also established that age, gender, availability, accessibility, and human resources have immense influence in the use of e-learning resources in public schools. These variables have a major contribution to a successful online learning program and in the development of the online learning skills of the learners. Likewise, Zimmerman and Kulikowich (2016) recognized the importance of online learning experience to fulfill task-specific performance in the online environment. The study revealed that students with online learning experience yield to higher confidence in learning online compared to students without prior experience.

The Laguna State Polytechnic University (LSPU) is one with the government in addressing the dramatic effect of COVID-19 on the education sector. In response to the directives of the CHED, the university conducted numerous studies to provide an assessment of the current status of the students relative to the possible implementation of alternative learning modality. The university collected information about students pertinent to their readiness and capability to migrate to online delivery of instruction. Thus, this study aimed to explore the factors influencing the online learning self-efficacy of teacher education students at LSPU, Philippines. It also assessed the perceived level of readiness for online learning, coping strategies used, and the familiarity and capability with educational technologies. This will provide empirical data which would serve as salient inputs to guide the university on transitioning from face-to-face set-up to flexible learning system such as online learning modality.

\subsection{Background of the Study}

Readiness is an element that is frequently used and measured in distance learning and online learning researches [12]. It has been established that readiness is central to a successful online learning experience. The changing demands are associated with online learning concerning technology, learning management, pedagogical practice, and social roles that necessitate essential preparation from the students' end [13]. To develop a scale to measure online learning readiness, Hung, Chou, Chen \& Own (2010) identified five core dimensions of the said construct: self-directed learning, motivation for learning, computer and internet self-efficacy, learner's control, and online communication self-efficacy. These dimensions are consistent with the definition of online learning readiness set forth by reference [15], who pioneered the concept of readiness for online learning. Warner, Christie, and Choy (1998) defined online learning readiness as students' preferences for taking online courses compared to classroom-based courses and students' perceived levels of confidence and competence in learning autonomously and in using the Internet and computer-mediated communication for learning purposes. Further, Callo and Yazon (2020 simplified the definition of preparedness, willingness, and motivation to enroll in an online teaching 
and learning environment in their study to explore the factors affecting readiness in alternative learning delivery mode.

Online learning requires specific skills to achieve high learning outcomes. Students should certainly have fundamental computer skills and knowledge about IT before taking online classes, $[4,5]$. Knowledge gain in an online learning environment is a function of their computer skills [17]. It is revealed that students with higher computer skills tend to gain more knowledge in web-based courses. It was further contended by Fakilende, Yusuf \& Agdebja (2014) that readiness for online learning is determined by access to the Internet, functional ICT skills, and appropriate independent learning skills. Students' familiarity and capability with educational technology applications are essential as well as effective online learning.

Lack of familiarity and experience in educational technologies could translate to significant demands for ICT support, particularly to courses that require laboratories and studio spaces as part of traditional experience. Students' capabilities and limitations on online learning should be recognized to encourage active learning [13]. Besides, the accessibility of computers and other learning platforms favors higher knowledge about ICT. Thus, the students must be skillfully prepared for the demand for online learning concerning technology. This is argued by reference [7] that the institution should look into the issue of familiarity of online learning technology among students before introducing the online learning system to evaluate whether students are comfortable with the learning tools.

Self-efficacy is a key aspect to achieve success in an online learning environment [8]. Online learning self-efficacy pertains to the belief regarding how well an individual can perform the actions to meet challenges and complete tasks effectively in the online environment. It has been established in the literature that self-efficacy is significantly associated with students' academic achievement [19-23]. Students with high online learning self-efficacy are more likely to be successful in online courses [11]. The concept of self-efficacy is rooted in the work of Bandura (1977), which explains the belief regarding how well an individual can perform the actions to meet challenges and complete tasks effectively. An individual's beliefs surrounding their levels of self-efficacy influence how they feel and think about themselves. It is an outcome of an individual's evaluation of past performance and the perceived level of competency he holds. Students' self-judgment about their capabilities to accomplish an online course is crucial for their satisfaction with online courses [8]. The role of self-efficacy in online learning environments is still in need of more investigations. More research is needed to develop an understanding of the nature of the relationship between online learning self-efficacy and the online learning environment [25].
Further, self-efficacy in technology is well studied but not much in the context of the learning environment and social interaction [8]. However, reference [11] contended that online learning self-efficacy must be explored not only in technology use but in the online learning environment and time management aspects.

\section{Objectives}

This study examined the causal relationship of students' perception of online learning modality from groups with and without online learning experience to their online learning self-efficacy. Specifically, it answered the following questions:

1. 1. What is the perceived level of the respondents' online readiness, coping ability to online learning, familiarity and capability to educational technology tools, and learning self-efficacy in terms of (1) learning in the online environment; (2) time management; and (3) technology use?

2. 2. Do the respondents perceive online readiness, coping strategies, and familiarity and capability to educational technologies significantly predict their self-efficacy in online learning?

\section{Methods}

\section{Research Design}

This study utilized a correlational research design to answer the research questions. The purpose of this research design is to analyze the association between variables and examine whether one variable can predict another [26]. In this study, the predicting variables are the respondents' readiness for online learning, coping strategies used, and familiarity and capability with educational technologies, while the outcome variable is the online learning self-efficacy.

\section{Respondents}

The participants of this study were 387 (57\%) out of 680 Teacher Education students from Laguna State Polytechnic University, San Pablo City, Laguna, Philippines. These students are previously enrolled in the academic year 2019-2020. The respondents are composed of $71.1 \%$ females and $23.8 \%$ males, while $5.1 \%$ of respondents prefer not to state their sex identity. The respondent's ages range from 18 to 42 . The mean age of the respondents is 20.36 where the majority $(80.80 \%)$ came from the age bracket of 18 to 20 years. The respondents are undergraduate students with $45 \%$ freshmen, $44.7 \%$ sophomores, and $10.3 \%$ juniors. Different academic programs were represented including elementary, 
secondary, technical-vocational, and physical education courses. A wide variety of specializations were also considered such as English, Filipino, Mathematics, Science, Social Studies, Home Economics, Food and Safety Management, Automotive Technology, Electronics Technology, Electrical Technology, Garments/Fashion, and Design, Industrial Arts, and Physical Education.

In terms of respondents' online learning experience, 246 respondents have not completed any online learning course, while 141 respondents stated that they have experienced substantial learning experience in the online environment. However, to continue the disrupted the teaching and learning at LSPU due to enhanced community quarantine, teachers and students were instructed and shifted to use online learning modality as part of the learning contingency plan on Flexible learning of the university. The respondents were provided three months of experience in the online learning environment. In terms of internet connection, $45.7 \%$ of the respondents have a mobile prepaid internet connection, $25.1 \%$ have a mobile postpaid connection, $18.2 \%$ have a fiber internet connection while $11 \%$ have other means of connection such as cable network. The respondents' availability of learning tools for online learning was also solicited, 96.6\% having smartphone conducive for online learning, $41.3 \%$ have desktop/ laptop, $10.9 \%$ have a printer, and $9.8 \%$ have smart television. Other respondents stated that they have tablets/ iPad, smartwatch, e-reader, storage devices, and radio transistors available for learning online. It should be noted that the respondents can have more than one learning tool at the same time.

\section{Instruments}

This study utilized a content-validated researcher-made instrument entitled Transition to Flexible Learning Modality Survey (TFLMS). The instrument was developed based on previous studies and literature. Research studies (Callo \& Yazon, 2020; Kwaah \& Essilfie, 2017; Peechapol et al., 2018; Zimmerman and Kulikowich, 2016) were used as references to identify the framework to develop the instrument appropriate for both respondents with and without online learning experience. The researcher asked permission from the respective authors to adapt their developed instruments and revise according to the purposes of the study. The developed instrument gained a Cronbach's alpha $=0.96$ indicating excellent internal consistency. Moreover, this online survey is composed of the following subscales:

1. Respondent's Profile - This component determines the respondents' profile in terms of age, sex, academic program, course specialization, learning preference, and available learning resources. It also determines whether the students have substantial experience in online learning.
2. Perceived Readiness to Online Learning - This is a four-item scale that determines the students' readiness and willingness to enroll in an online learning course program. The items in this instrument are based on the simplified definition of Callo and Yazon (2020) of online learning readiness. It is a 6-point Likert scale ranging from 1- Very Low" to 6-"Very High".

3. Coping Ability to Online Learning - This is a 10-item questionnaire that assesses the level of coping ability of the students to an online learning environment. The items were constructed based on the previous study of Kwaah and Essilfie (2017) which explores the stress and coping mechanisms of university students in distance education. It is measured on a 5-point Likert scale which ranges from 1-"Never" to 2-"Always".

4. Familiarity and Capability to Educational Technology Applications - This is a 10 -item questionnaire that assesses the students' familiarity and capacity to use educational technology applications and tools. The items were based on the study of Callo and Yazon (2018) and a national survey piloted by the Department of Information and Communication Technology (DICT) of the Philippines. It is measured on a 6-point Likert scale ranging from 1-"Very Unfamiliar and Incapable" to 6 -"Very Familiar and Capable"

5. Online Learning Self-Efficacy - The items in this scale were adapted from the study of Zimmerman and Kulikowich (2016). The authors ask permission to use the scale from the developer via email. Upon confirmation, the researcher validated the instrument's appropriateness to the target sample. This scale is composed of 22 items that measure the online learning self-efficacy of the students in terms of (1) learning in the online environment; (2) time management; and (3) technology use. It is measured on a 6-point Likert scale from 1-“Poor" to 6 "Expert".

\section{Data Collection}

The researchers administered an online survey encoded in Google Forms in June 2020 right after the three-month-long implementation of enhanced community quarantine in the Philippines. The online survey was sent through electronic mails to the participants with an informed consent form stating that their participation is voluntary and their responses will be treated with high-confidentiality. This method was used because of its cost-effectivity characteristic and its convenience to distribute the questionnaires. The researchers ensured the high-response rate by checking weekly the number of responses and following up with the participants who have not yet responded through private and group messages. 


\section{Data Analysis}

The researcher used descriptive statistics such as mean and standard deviation to analyze the response of the students. The Cronbach's alphas were also computed to establish the reliability and internal consistency of the research instrument. Pearson product-moment correlation test was initially used to analyze the association among the variables involved in the study. To determine the causal relationship, multiple regression analysis was employed to identify the significant predictors of online learning self-efficacy.

\section{Results}

Table 1 presents the perceived readiness of the respondents to learn in an online environment. Based on the data in Table 1, all indicators were verbally interpreted as "Above Average." This reveals that the student's likelihood to enroll and recommend online learning to other students is above average. Thus, the perceived level of readiness of the students is above average as indicated by an overall mean value of $3.81(\mathrm{SD}=0.90)$.

Table 2 presents the level of coping ability of the students to online learning modality. Indicators 7 and 8 registered the highest means with $4.36(\mathrm{SD}=0.86)$ and 4.05 $(\mathrm{SD}=0.79)$ respectively, which are both interpreted as "Always," while Indicator 3 got the lowest mean value of $3.17(\mathrm{SD}=1.12)$, which is verbally interpreted as "Sometimes." It implies that the respondents maintain positivity despite facing struggles in learning through virtual platforms. Further, respondents are less likely to ask for academic assistance from their family members since they are already self-directed learners as college students. Indicators $1,2,4,5,6,9,10$ were verbally interpreted as "Almost Always." In summary, the coping strategies presented in Table 2 are used almost always by the students to manage the teaching-and-learning activities in a virtual classroom.

Table 1. Readiness to Online Learning of the Respondents

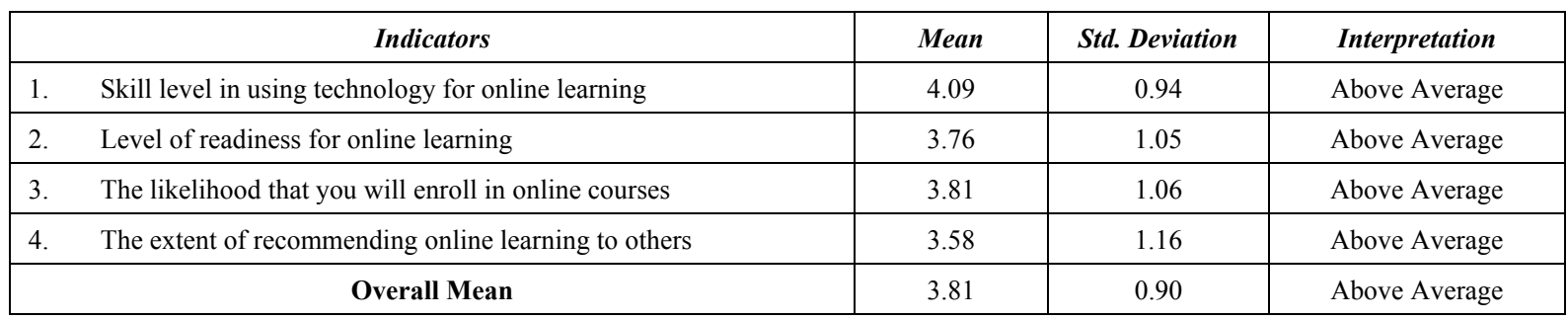

Legend: 1-1.83 -Very Low; 1.84-2.66, Low; 2.67-3.49 - Average; 3.50-4.32 - Above Average; 4.33-5.15 - High; 5.16-6 - Very High

Table 2. Coping Strategies for Online Learning

\begin{tabular}{|ll|c|c|c|}
\hline \multicolumn{1}{|c|}{ Indicators } & Mean & Std. Deviation & Interpretation \\
\hline 1. & Accept the situation and learn to live with it. & 3.77 & 0.85 & Almost Always \\
\hline 2. & Ask academic support from teachers and professionals. & 3.75 & 0.98 & Almost Always \\
\hline 3. & Ask for help from family members who know online learning. & 3.17 & 1.12 & Sometimes \\
\hline 4. & Get emotional support from family members and friends. & 3.63 & 1.02 & Almost Always \\
\hline 5. $\quad$ Isolate me from any distractions when I am studying. & 3.96 & 0.93 & Almost Always \\
\hline 6. & Manage my time effectively by creating a timeline of activities. & 3.63 & 0.94 & Almost Always \\
\hline 7. & Pray and meditate to calm the mind. & 4.36 & 0.86 & Always \\
\hline 8. & Stay positive and optimistic despite loads of work. & 4.05 & 0.79 & Always \\
\hline 9. & Take a break from academic works by watching TV, listening to music, or \\
& playing. & 4.15 & 0.89 & Almost Always \\
\hline 10. $\quad$ Try to practice online or flexible learning platforms on my own. & 3.60 & 0.91 & Almost Always \\
\hline & Overall Mean & 3.81 & 0.53 & Almost Always \\
\hline
\end{tabular}

Legend: 1-1.8 - Never; 1.9-2.6 - Rarely; 2.7-3.4 - Sometimes; 3.5-4.2 -Almost Always; 4.3-5 - Always 
Table 3 shows the familiarity and capability of the respondents in using educational technology tools. The data reveals that the students are very familiar and capable of Social Media e.g. Facebook, Twitter, and Instagram, and Messaging Tools e.g. Gmail, yahoo mail, and messenger as revealed by their mean values of $5.53(\mathrm{SD}=0.79)$ and 5.22 $(\mathrm{SD}=0.88)$ respectively. This can be attributed to the fact that the students are immersed in social media platforms which are widely used to connect and share with other people. This also implies that the respondents are well introduced to electronic communication tools which are very essential to online learning. These learning tools are very accessible to students and are easy to use. It can also be noted on the table that the respondents are unfamiliar and incapable of using statistical tools e.g. SPSS, Stata, and
MS Access. This can be attributed to the fact that the majority of the respondents are not yet taking Statistics and Research classes where this tool can be encountered. Likewise, these tools require technical skills and are considered tools for experts.

Table 4 reveals the online learning self-efficacy of the respondents as to learning in the online environment. The overall mean value of $3.76(\mathrm{SD}=0.91)$ reveals that the respondents rated as very good at performing the tasks listed. The data table also reveals that all tasks can be performed by the students satisfactorily. This indicates that respondents can handle holding classes in virtual rooms, address issues and challenges relevant to technical aspects, and learn effectively in an online environment.

Table 3. Level of Familiarity and Capability to Educational technology Tools

\begin{tabular}{|ll|c|c|c|}
\hline & \multicolumn{1}{|c|}{ Indicators } & Mean & Std. Deviation & Interpretation \\
\hline 1. & Office Productivity Tools (Microsoft Office, LibreOffice, etc.) & 4.78 & 1.08 & Familiar and Capable \\
\hline 2. & Social Media (Facebook, Twitter, Instagram) & 5.53 & 0.79 & Very Familiar and Capable \\
\hline 3. & Online Collaboration Tools (Google Docs, OneDrive, etc.) & 4.47 & 1.14 & Familiar and Capable \\
\hline 4. & Virtual Classroom (Google Classroom, Edmodo, Schoology, etc.) & 4.10 & 1.16 & Fairly Familiar and Capable \\
\hline 5. & Messaging Tools (Gmail, yahoo mail, messenger, etc.) & 5.22 & 0.88 & Very Familiar and Capable \\
\hline 6. & Video sharing sites (YouTube, Vimeo) & 4.89 & 1.01 & Familiar and Capable \\
\hline 7. & Videoconferencing applications (Zoom, Google Meet, Microsoft & 3.92 & 1.23 & Fairly Familiar and Capable \\
\hline 8. & Teams, etc.) & 2.57 & 1.32 & Unfamiliar and Incapable \\
\hline 9. & Programming Tools (Windows Movie Maker, OBS) & 2.64 & 1.35 & Somewhat Familiar and Capable \\
\hline 10. & Video and image editing tools (Adobe Photoshop, Canva) & 3.92 & 1.33 & Fairly Familiar and Capable \\
\hline & $\quad$ Overall Mean & 4.20 & 0.76 & Fairly Familiar and Capable \\
\hline
\end{tabular}

Legend: 1-1.83 -Very Unfamiliar and Incapable; 1.83-2.66, Unfamiliar and Incapable; 2.67-3.49 - Somewhat Familiar and Capable; 3.50-4.32 Fairly Familiar and Capable; 4.33-5.15 - Familiar and Capable; 5.16-6 - Very Familiar and Capable

Table 4. Online Learning Self-Efficacy as to Online Environment

\begin{tabular}{|ll|c|c|c|}
\hline \multicolumn{1}{|c|}{ Indicators } & Mean & Std. Deviation & Interpretation \\
\hline 1. & $\begin{array}{l}\text { Communicate effectively with technical support via e-mail, mobile phone, or live } \\
\text { online chat. }\end{array}$ & 4.23 & 1.20 & Very Good \\
\hline 2. & Overcome technical difficulties on my own. & 3.73 & 1.20 & Very Good \\
\hline 3. & Learn to use a new type of technology efficiently. & 4.06 & 1.10 & Very Good \\
\hline 4. & Learn while you and your instructor are in distant places. & 3.94 & 1.07 & Very Good \\
\hline 5. & Learn without being in the same room as other students. & 3.91 & 1.13 & Very Good \\
\hline 6. & $\begin{array}{l}\text { Communicate using asynchronous technologies (discussion boards, padlet, e-mail, } \\
\text { etc.) }\end{array}$ & 3.52 & 1.19 & Very Good \\
\hline 7. & Complete a group project entirely online. & 3.62 & 1.21 & Very Good \\
\hline 8. & $\begin{array}{l}\text { Use synchronous technology to communicate with others (such as Skype, Google } \\
\text { meet, Zoom). }\end{array}$ & 3.57 & 1.26 & Very Good \\
\hline 9. & Use the library's online resources efficiently. & 3.42 & 1.20 & Very Good \\
\hline 10. & $\begin{array}{l}\text { When a problem arises, promptly ask questions in the appropriate forum (e-mail, } \\
\text { discussion board, etc.) }\end{array}$ & 3.64 & 1.15 & Very Good \\
\hline & $\quad$ Overall Mean & 3.76 & 0.91 & Very Good \\
\hline
\end{tabular}

Legend: 1-1.83 -Poor; 1.83-2.66, Fair; 2.67-3.49 - Good; 3.50-4.32 - Very Good; 4.33-5.15 - Proficient; 5.16-6 - Expert 
Table 5. Online Learning Self-Efficacy as to Time Management

\begin{tabular}{|cl|c|c|c|}
\hline & Indicators & Mean & Std. Deviation & Interpretation \\
\hline 1. & Manage time effectively & 4.10 & 1.21 & Very Good \\
\hline 2. & Complete all assignments on time & 4.51 & 1.23 & Proficient \\
\hline 3. & Meet deadlines with minimal reminders. & 4.07 & 1.10 & Very Good \\
\hline 4. & Focus on schoolwork when faced with distractions. & 3.61 & 1.19 & Very Good \\
\hline 5. & Develop and follow a plan for completing all required work on time. & 4.13 & 1.12 & Very Good \\
\hline & Overall Mean & 4.08 & 0.96 & Very Good \\
\hline
\end{tabular}

Legend: 1-1.83 -Poor; 1.83-2.66, Fair; 2.67-3.49 - Good; 3.50-4.32 - Very Good; 4.33-5.15 - Proficient; 5.16-6 - Expert

Table 6. Online Learning Self-Efficacy as to Technology Use

\begin{tabular}{|ll|c|c|}
\hline \multicolumn{1}{|c|}{ Indicators } & Mean & Std. Deviation & Interpretation \\
\hline 1. & Navigate online course materials efficiently. & 3.73 & 0.98 \\
\hline 2. & Find the course syllabus online. & 3.76 & Very Good \\
\hline 3. & $\begin{array}{l}\text { Communicate effectively with my instructor via e-mail (Gmail, yahoo } \\
\text { mail, messenger) }\end{array}$ & 4.35 & \multirow{2}{*}{1.17} \\
\hline 4. & Submit assignments to an online dropbox such as Google drive. & 4.01 & 1.23 \\
\hline 5. & Navigate the online grade book. & 3.70 & 1.20 \\
\hline 6. & Search the Internet to find the answer to a course-related question. & 4.12 & 1.13 \\
\hline 7. & Search the online course materials. & 4.04 & Very Good \\
\hline & Overall Mean & 3.96 & Very Good \\
\hline
\end{tabular}

Legend: 1-1.83 -Poor; 1.84-2.66, Fair; 2.67-3.49 - Good; 3.50-4.32 - Very Good; 4.33-5.15 - Proficient; 5.16-6 - Expert

Table 5 illustrates the online learning self-efficacy of the respondents as to time management. The overall mean value of $4.08(\mathrm{SD}=0.96)$ is interpreted as "Very Good," which indicates that the respondents believed that they are capable of managing their time effectively. It also notable that indicator 2 gained the highest mean value of 4.51 $(\mathrm{SD}=1.23)$, which means that students can complete assignments given to them on time.

Table 6 reveals the online learning self-efficacy of the respondents as to technology use. The table shows that the respondents are considered very good at performing tasks relate to technology use as revealed by the overall mean value of $3.96(\mathrm{SD}=0.89)$. This means that respondents are capable of using technology in an online learning environment. It can also be noted that indicator 3 rated the highest mean value of $4.35(\mathrm{SD}=1.17)$. This implies that the respondents are capable of communication tools effectively such as Gmail, Yahoo Mail, and messenger.

Table 7 presents the results of the test of correlation among the study variables. The table clearly illustrates the positive significant relationships at 0.05 alpha level among all study variables as revealed by their p-values and r-values based on the correlation guide of Evans (1996). Correlation analysis reveals that perceived readiness of the respondents $(\mathrm{r}=.763, .609, .682)$, respectively and familiarity and capability to educational technology tools $(\mathrm{r}=.718, .524, .664)$, respectively are strongly correlated to the three domains of online learning self-efficacy (learning in the online environment, time management, and technology use) as indicated by the r-values which all lies between 0.50 and 1 . This is reasonable since the perceived readiness to online learning of the respondents explains their beliefs on accomplishing learning tasks in virtual reality. Likewise, the familiarity and capability of educational technology learning tools are fundamental to self-efficacy in online learning. On the other hand, coping strategies used by the respondents $(\mathrm{r}=.447, .464, .414)$ are revealed to have a moderate degree of association to three domains of online learning self-efficacy as indicated by the $r$ values which all lie between 0.30 and 0.49 . This can be attributed to the fact that students use diverse coping strategies to cope in an online learning environment. It can also be noted on the table that variables 4 and 6 demonstrated the strongest correlation with r-value of .872 . This signifies that technology use is important in learning in an online environment. The use of technology simplifies access to educational resources, support independent learning, and create virtual connections which are considered key elements in online education.

Table 7. Test of Correlation among the Study Variables

\begin{tabular}{|c|c|c|c|c|c|c|}
\hline Variables & 1 & 2 & 3 & 4 & 5 & 6 \\
\hline $\begin{array}{c}\text { Online } \\
\text { Readiness }\end{array}$ & --- & - & & . & & \\
\hline $\begin{array}{c}\text { Coping } \\
\text { Strategies }\end{array}$ & $391^{* *}$ & --- & & & & \\
\hline $\begin{array}{c}\text { Familiarity } \\
\text { and } \\
\text { Capability }\end{array}$ & $0.619^{* *}$ & $.314^{* *}$ & --- & & & \\
\hline $\begin{array}{l}\text { Self-Efficacy } \\
\text { in Online } \\
\text { Environment }\end{array}$ & $763^{* *}$ & $.447^{* *}$ & $.718^{* *}$ & --- & & \\
\hline $\begin{array}{l}\text { Self-efficacy } \\
\text { in Time } \\
\text { Management }\end{array}$ & $.609^{* *}$ & $.464^{* *}$ & $.524^{* *}$ & $.801^{* *}$ & --- & \\
\hline $\begin{array}{c}\text { Self-efficacy } \\
\text { in } \\
\text { Technology } \\
\text { Use }\end{array}$ & $.682^{* *}$ & $.414^{* *}$ & $.664^{* *}$ & $.872^{* *}$ & $.747^{* *}$ & --- \\
\hline
\end{tabular}

$* \mathrm{p}<.05, * * \mathrm{p}<0.1$ 
Table 8. Regression Analysis of Online Learning Self-Efficacy as Outcome Variable

\begin{tabular}{|c|c|c|c|c|c|}
\hline & \multicolumn{2}{|c|}{$\begin{array}{c}\text { Unstandardized } \\
\text { Coefficient }\end{array}$} & $\begin{array}{c}\text { Standardized } \\
\text { Coefficient }\end{array}$ & \multicolumn{2}{|l|}{} \\
\hline Variables & B & SE & $\boldsymbol{\beta}$ & $\mathbf{t}$ & Sig. \\
\hline Constant & -.479 & .208 & & -2.306 & .022 \\
\hline $\begin{array}{c}\text { Online } \\
\text { Readiness }\end{array}$ & .426 & .038 & .445 & 11.125 & .000 \\
\hline $\begin{array}{c}\text { Coping } \\
\text { Strategies }\end{array}$ & .310 & .053 & .192 & 5.822 & .000 \\
\hline $\begin{array}{c}\text { Familiarity } \\
\text { and } \\
\text { Capability }\end{array}$ & .384 & .043 & .342 & 8.834 & .000 \\
\hline
\end{tabular}

$\mathrm{N}=387 \quad \mathrm{R}^{2}=.649 \quad$ Adj. $\mathrm{R}^{2}=.646$

Multiple Regression analysis was employed to explain the online learning self-efficacy of the respondents based on their online readiness, coping strategies, and familiarity, and capability with educational technologies. The equation below presents the predicted online learning self-efficacy of the respondents based on the data analysis;

$\mathrm{OLSE}=.479+.426 \mathrm{OR}+.310 \mathrm{CS}+.384 \mathrm{FAC}$, where

OLSE $=$ Online Learning Self-Efficacy, OR $=$ Online Readiness, $\mathrm{CS}=$ Coping Strategies, and FAC $=$ Familiarity and Capability.

In terms of online learning self-efficacy, Table 8 revealed that perceived readiness $(\beta=.426, p=.000)$, coping strategies $(\beta=.310, p=.000)$, and familiarity and capability ( $\beta=.384, p=.000)$ significantly predict the online learning self-efficacy of the respondents as revealed by their standardized coefficients and p-values. Based on the equation model, a one-unit change in online readiness, the model predicts a .426-unit change in online learning self-efficacy assuming all other factors are held constant. Similarly, a one-unit change in coping strategies would translate to a .310 -unit change in the online learning self-efficacy of the respondents, keeping other predictors fixed. Further, a one-unit change in familiarity and capability to educational technology would result in a .384-unit change in online learning self-efficacy holding other variables constant. Further, the table reveals that $64.9 \%$ of the variance in the online learning self-efficacy of the respondents can be explained by their online readiness, coping strategies, and familiarity, and capability.

\section{Discussion}

The objective of this study is to explore the online learning self-efficacy of teacher education students at a state university in the Philippines. It assessed the level of perceived readiness, copings strategies to online learning, familiarity, and capability to educational technology tools, and the online learning self-efficacy of the respondents. It further determined whether perceived readiness, coping strategies, and familiarity and capability predict the online learning self-efficacy of the respondents.

Descriptive statistics revealed commendable results regarding the perceived readiness, copings strategies to online learning, familiarity, and capability to educational technology tools, and the online learning self-efficacy of the respondents. The coping strategies listed were adapted by the respondent almost always. Further, the respondents self-rated fairly satisfactory on the familiarity and capability to utilize technological tools. In terms of self-efficacy in the three subdomains, the respondents rated themselves very good in performing the task-specific online activities. However, the results also indicate that the respondents are only above average in terms of readiness to enroll in online learning. Reference [16] argued that these variables are crucial to the effective implementation of online learning modality. They further contended that well-designed online education is as effective as face-to-face instruction emphasizing the element of learning engagement and collaboration. Reference [6] emphasized the importance of assessing the role of the students in online learning. The characteristics of the students will serve as a basis for creating an effective online program that meets the demand of every student.

The correlation analysis established a positive linear association among the variables involved in the study. Perceived readiness for online learning and familiarity and capability with educational technology tools are strongly associated with the online learning self-efficacy of the respondents. On the other hand, coping strategies used by the students have a medium relationship with the respondent's online learning self-efficacy. These findings are widely supported by studies in the literature $[1,16,25,30]$. It is a fact that self-efficacy is influenced by various factors such as the variables under this current study. Reference [25] provided evidence of significant sources of self-efficacy in the context of online learning. These include online learning experience and knowledge, feedback and reward, and learner motivation and attitude. These are crucial factors that serve as a guide for designing online learning programs to foster students' self-efficacy. These sources are relevant if not the same to the variables considered in the study. Similarly, Bates and Khasawneh (2007) found that self-efficacy in the context of online learning is affected by four factors such as previous success in online learning, pre-course training, instructor's feedback, and online learning technology anxiety.

This study provided empirical evidence of the different contributing factors influencing the self-efficacy of the students to online learning. To foster online learning self-efficacy, the study revealed that students' perception of online readiness, coping strategies, and familiarity and capability to educational technology are predictive of online learning self-efficacy. These findings are supported by the study conducted by Callo and Yazon (2020) which explores the factors influencing the readiness of faculty and students on online teaching and learning. The study revealed that $67.1 \%$ of the variation on the online teaching and learning readiness score can be explained by 
respondents' familiarity and capability, preparation, device and access connectivity, self-efficacy, and experience with technology. Alqurashi (2017) also gave evidence about the predictive ability of online learning self-efficacy to students' satisfaction and perceived learning. The study further revealed that self-efficacy was the strongest and most significant predictor of perceived learning. This serves as a basis for developing a migration plan from conventional to online learning taking into account the diverse student-related factors. The online learning readiness of the students is crucial since it tells the extent of students' willingness to shift from conventional to online learning. Further, their familiarity and capability of learning tools relevant in the virtual environment are also necessary because it prepares the students to the technical aspects of virtual learning. The teachers must also consider the diverse background of the students to gauge the strategies students adapt to thrive in the current educational shift.

\section{Conclusions and Recommendations}

Online learning as a form of flexible learning system is a viable instructional response to mitigate the effects of the COVID-19 pandemic on the education sector. Research suggests that online learning has been shown to improve retention of information, take less time, and allow remote learning [33]. Despite the argument that online modality can reach rural and remote areas [34], it still challenges the "new normal" of higher education. It poses an educational challenge that inhibits the students to receive quality education because of no access to computer learning resources and a lack of fundamental skills required for this alternative learning system. Because of this, the implementation of this modality shall not create further digital divides among the students. Instead, it should create new opportunities to learn new perspectives of the educative process. Understanding the students' roles and characteristics in this pandemic pedagogy are crucial to effective implementation [16]. The students' self-efficacy in learning online shall be developed to promote higher academic achievement and engagement with the students. This can be done by examining the factors with immense influence on its improvement. These are online learning readiness, copings strategies used, and familiarity, and capability to online learning as revealed by the current study.

In this time of educational transition, the stakeholders must have a consensual agreement about the policies, guidelines, and action plans regarding the implementation of the distance learning program such as online learning. It is a must to have a high level of preparedness to adapt to the changes in the environment and adjust ourselves to different delivery modes, for instance, online learning in situations of pandemics [34]. The program should be viewed as a shared responsibility for the teachers, students, administrators, and other stakeholders to achieve a high success rate. The implementation of online education should be progressive rather than prescriptive. Thus, this study recommended the following:

1. The teachers are central to this educational transition. They must examine the students' characteristics and roles in an online program to provide the appropriate type of support and to better prepare them for the transition to online learning modality. Hence, teachers should acquire the necessary knowledge, skills, and attitudes towards implementing a successful online academic program.

2. The students should be prepared in terms of fundamental ICT and computer skills about learning in an online program. They must also be oriented on the technical aspects and standard procedures relevant to the online learning program. The learning management system and the relevant educational technology tools must be familiarized with the teachers and students to avoid misperception that leads to digital divides. This will help them plan the necessary coping strategies to survive online learning challenges. Likewise, the university must also provide technical assistance to the neediest students in terms of the provision of laptop/computer, gadgets, and internet connection.

3. The university may develop comprehensive policies and guidelines regarding the implementation of the online program. It should detail the specific roles and responsibilities of teachers, students, support personnel, and other stakeholders to create a smooth-sailing process of the online delivery mode. This will prevent the accumulation of loads of works to the teachers and students among others that will affect their well-being and will transpire to the implementation of the online learning delivery.

4. Pure online learning delivery cannot stand by itself due to students' differences as to geographical location, accessibility to learning resources, and their level of ICT skills. This modality should be supported by other distance learning modes such as modular learning to meet the needs of students in geographically-challenged areas, needs technical support, and are digital migrants. The development of learning modules should follow uniform guidelines that promote self-directed learning.

5. Relative to generalizing in the context of the study, the sample only accounts for one academic program. Likewise, the instrument used is a self-report which can be affected by their emotional willingness during answering the instrument. For future research directions, a larger sample may be considered to obtain more reliable results accounting for various colleges in the university. It is also recommended to use a qualitative research design to gauge the rich 
context and data about the respondents. Likewise, emotional related factors can also be considered for future research since the current study only accounts for the technical skills of the students.

\section{Acknowledgments}

The authors acknowledge the support extended by the administration of the Laguna State Polytechnic University for the publication of this research paper and for motivating all faculty members to actively engage in research undertakings.

\section{REFERENCES}

[1] Martin, F., Stamper, B., Flowers, C., "Examining student perception of their readiness for online learning: Importance and confidence," Online Learning, vol. 24, no. 2, pp. 38-58, 2020. https://DOI.org/10.24059/olj.v24i2.2053.

[2] Deng, L., Tavares, N, "From Moodle to Facebook: Exploring students' motivation and experiences in online communities," Computers \& Education, vol. 68, pp. 167176, 2013. https://DOI:org/10.1016/j.compedu.2013.04.028.

[3] Nguyen, T., "The Effectiveness of Online Learning: Beyond No Significant Difference and Future Horizons," MERLOT Journal of Online Learning and Teaching, vol. 11, no. 2, pp. 309-319, 2015.

[4] Lee, J., Mendlinger, S., "Perceived self-efficacy and its effect on online learning acceptance and student satisfaction," Journal of Service Science and Management, vol. 4, pp. 243-252, 2011. https://DOI.org/10.4236/jssm.2011.43029.

[5] Forson, I. K., Vuopala, E., "Online learning readiness: a perspective of students enrolled in distance education in Ghana," The Online Journal of Distance Education and e-Learning, vol. 7, no. 4, pp. 277-294, 2019.

[6] Colorado, J.T., Eberle, J., "Student demographics and success in online learning environments," Emporia State Research Studies, vol. 46, no. 1, pp. 4-10, 2010.

[7] Islam, M. A. "Effect of Demographic Factors on E-Learning Effectiveness in a Higher Learning Institution in Malaysia," International Education Studies, vol. 4, no. 1, pp. 112-121, 2011.

[8] Shen, D., Cho, M., Tsai, C., Marra, R., "Unpacking online learning experiences: Online learning self-efficacy and learning satisfaction," The Internet and Higher Education, vol. 19, pp. 10-17, 2013. http://dx.DOI.org/10.1016/j.ihedu c. 2013.04 .001

[9] Naresh, B., Reddy, D. B. S., Pricilda, U., "A Study on the Relationship between Demographic Factor and e-Learning Readiness among Students in Higher Education," Sona Global Management Review, vol. 10, no. 4, pp. 1-11, 2016.

[10] Owate, C. N., Afolabi, M., Akanwa, P. C., "Demographic variables and students use of e-learning resources in public secondary schools libraries in Rivers State of Nigeria,"
International Journal of Educational Administration and Policy Studies, vol. 9, no. 2, pp. 11-27, 2017. http://DOI.org/10.5897/IJEAPS2016.0487

[11] Zimmerman, W. A., Kulikowich, J. M., “Online learning self-efficacy in students with and without online learning experience," American Journal of Distance Education, vol. 30, no. 3, pp. 180-191, 2016. https://DOI.org/10.1080/08923647.2016.1193801.

[12] Kaymak, Z. D., Horzum, M. B. "Relationship between Online Learning Readiness and Structure and Interaction of Online Learning Students," Educational Sciences: Theory \& Practice, vol. 13. No. 3, pp. 1792-1797. DOI: 10.12738/estp.2013.3.1580

[13] Vonderwell, S., Savery, J., “Online learning: students' role and readiness," The Turkish Online Journal of Educational Technology, vol. 3, no. 3, pp 38-42, 2004

[14] Hung, M., Chou, C., Chen, C., Own, Z. -Y. "Learner readiness for online learning: Scale development and student perceptions," Computers in Education, vol. 55, no. 3, pp. 1080-1090, 2010. https://doi.org/10.1016/j.compedu.2010. 05.004

[15] Warner, D., Christie, G., Choy, S. "Readiness of VET clients for flexible delivery including online learning," Brisbane: Australian National Training Authority, 1998.

[16] Callo E. C, Yazon, A. D. "Exploring the factors influencing the readiness of faculty and students on online teaching and learning as an alternative delivery mode for the new normal," Universal Journal of Educational Research, vol. 8, no. 8, pp. 3509-3518, 2020. http://DOI.org/10.13189/ujer.2020.08082 6.

[17] Rakap, S., "Impacts of learning styles and computer skills on adult students' learning online," The Turkish Online Journal of Educational Technology, vol. 9, no. 2, pp. 108-115, 2010.

[18] Fakilende, C. O., Yusuf, M. O., Adegbija, V. M., "Readiness for online learning in higher education: A mixed-methods assessment of students at a Nigerian university," Malaysian Journal of Distance Education, vol. 16, no. 1, pp. 37-57, 2014.

[19] Bates, R., Khasawneh, S., "Self-efficacy and college students' perceptions and use of online learning systems," Computers in Human Behavior, vol. 23, pp. 175-191, 2007.

[20] Cascio M., Botta V., Anzaldi V. "The role of self-efficacy and internal locus of control in online learning," Journal of e-Learning and Knowledge Society, vol. 9, no. 3, pp. 95-106, 2013.

[21] Goulão, M. F., "The Relationship between Self-Efficacy and Academic Achievement in Adults' Learners," Athens Journal of Education, vol. 1, no. 3, pp. 237-246, 2014. https://DOI.org/10.30958/aje.1-3-4.

[22] Rodriguez, B. C. P., Armellini, A., "Developing Self-Efficacy through a Massive Open Online Course on Study Skills," International Council for Open and Distance Education, vol. 9, no. 3, pp. 335-343, 2017.

[23] Taipjutorus, W., Hansen, S., Brown, M., "Investigating a relationship between learner control and self-efficacy in an online learning environment," Journal of Open, Flexible, and Distance Learning, vol. 16, no. 1, pp. 56-69, 2012. 
[24] Bandura, A., "Self-efficacy: Toward a unifying theory of behavioral change," Psychological Review, vol. 84, no. 2, p. 191, 1977. https://DOI.org/10.1037/0033-295X.84.2.191.

[25] Alqurashi, E., "Self-efficacy in an online learning environment: A literature review," Contemporary Issues in Education Research, vol. 9, no. 1, pp. 45-52, 2016.

[26] Creswell, J.W. 'Quantitative Method.' in Research designs: Quantitative, qualitative, and mixed-method approaches, $4^{\text {th }}$ ed. Thousand Oak, California. SAGE Publications, Inc., 2013, pp. 199-231.

[27] Kwaah, C. Y., Essilfie, G. "Stress and coping strategies among distance education students at the University of Cape Coast, Ghana," Turkish Online Journal of Distance Education, vol. 18, no. 3, pp. 120-134, 2017. EISSN $1302-6488$

[28] Peechapol, C., Na-Songkhla, J., Sujiva. S., Luangsodsai, A., "An exploration of factors influencing self-efficacy in online learning: a systematic review," International Journal of Emerging Technologies in Learning, vol. 13, no. 9, pp. 64-86, 2018. http://DOI.org/10.3991/ijet.v13i09.8351

[29] Evans, J. D. "Straight Forward Statistics for the Behavioral Sciencesll." Pacific Grove, CA: Brooks/Cole Publishing. 1996.

[30] Rohatgi, A., Scherer, R., Hatlevik, O. E. "The role of ICT self-efficacy for students' ICT use and their achievement in a computer and information literacy test," Computer and Education, vol. 102, no. 1, pp. 103-116, 2016. https://doi.org/10.1016/j.compedu.2016.08.001

[31] Alqurashi, E. (2017). Self-Efficacy and the Interaction Model as Predictors of Student Satisfaction and Perceived Learning in Online Learning Environments (Doctoral dissertation, Duquesne University). Retrieved from http://dsc.duq.edu/etd/194.

[32] Bates, R., \& Khasawneh, S. "Self-efficacy and college students' perceptions and use of online learning systems," Computers in Human Behavior, vol. 23, no. 1, pp. 175-191, 2007. https://doi.org/10.1016/j.chb.2004.04.004

[33] Li, C., \& Lalani, F. (2020, April 29). The rise of online learning during the COVID-19 pandemic. World Economic Forum.

https://www.weforum.org/agenda/2020/04/coronavirus-edu cation-global-covid19-online-digital-learning/

[34] Dhawan, S. Online Learning: "A Panacea in the Time of COVID-19 Crisis." Journal of Education Technology Systems, vol. 49, no. 1, pp. 5-22, 2020. https://doi.org/10.1177\%2F0047239520934018

[35] Department of Information and Communication Technology (2020). The New Normal on Digital Government: Work From Home Baseline Survey for Government Personnel, https://docs.google.com/forms/d/e/1FAIpQLSeTYg71DIDH nBqU0MEXSBoRJC9MhrwcWcaTfG3GH2KrysGFKQ/vie wform 